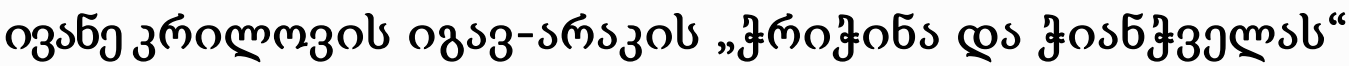

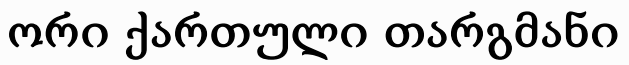

\author{
bjos slsosymmzo \\ oszmi zmzjвs

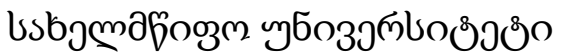

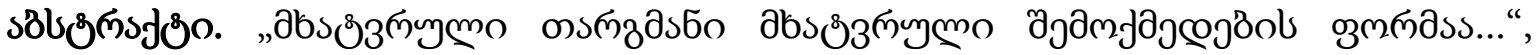

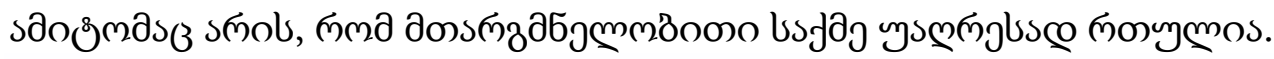

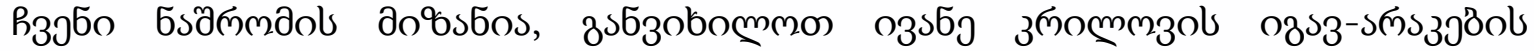

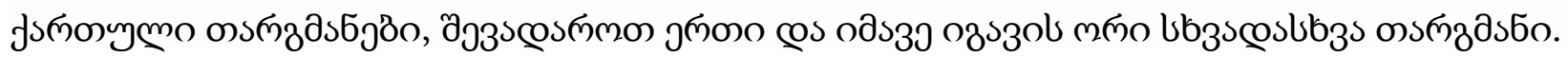

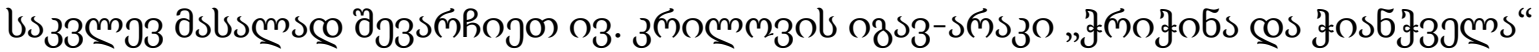

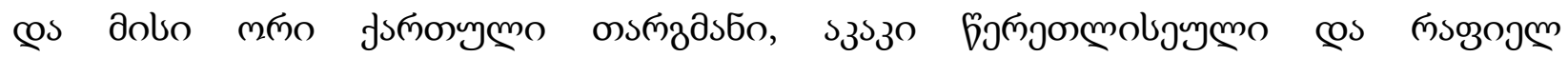

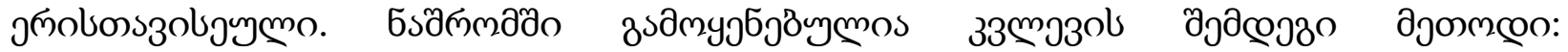

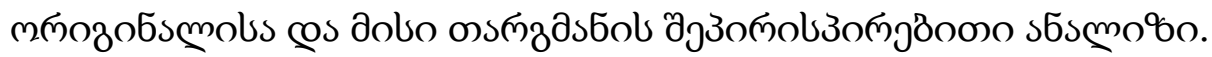

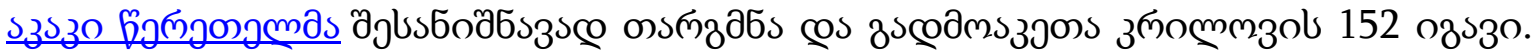

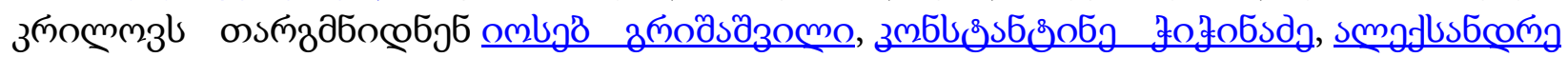

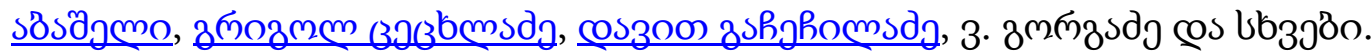

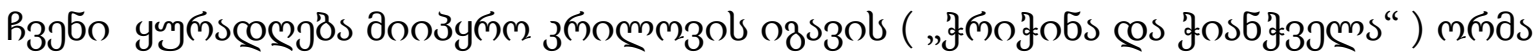

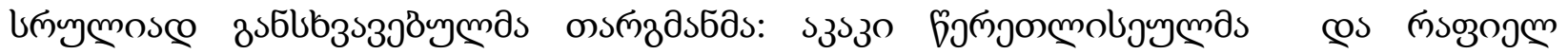
jnolonszoljaymas.

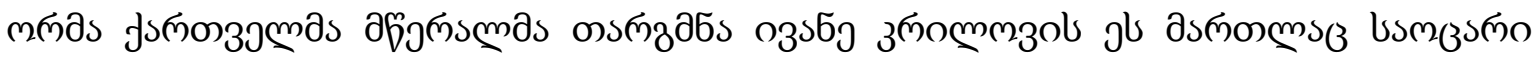

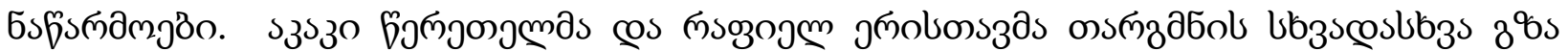
som̧os.

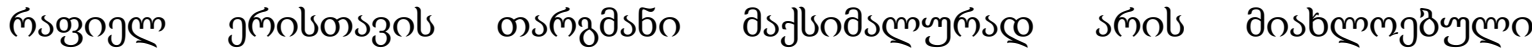

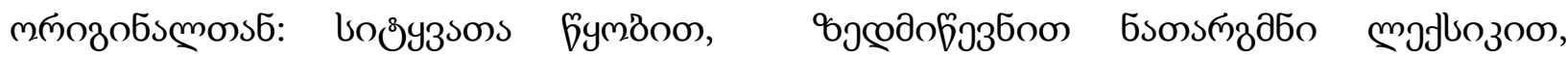

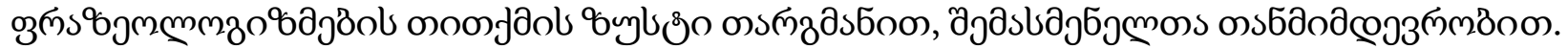

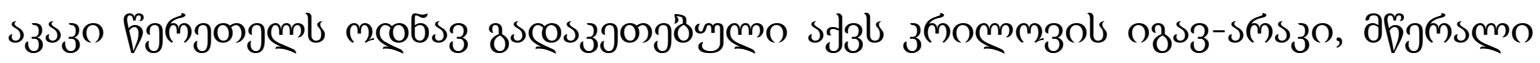

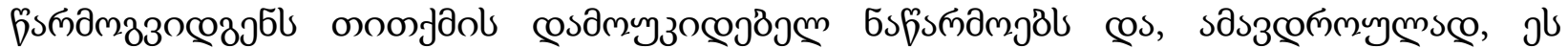

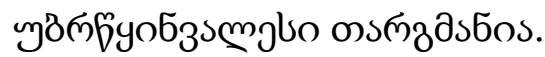

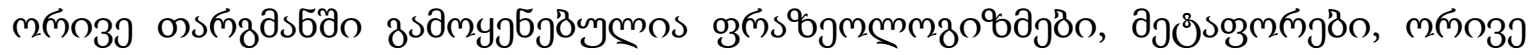

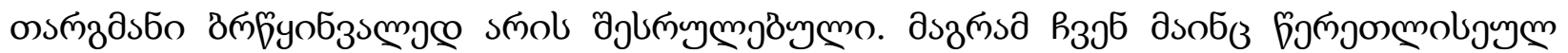

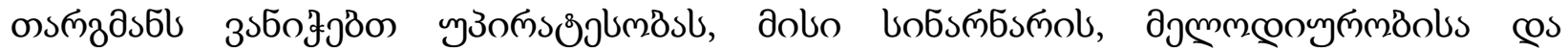

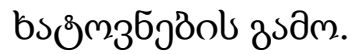




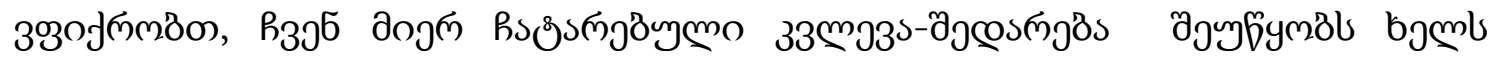

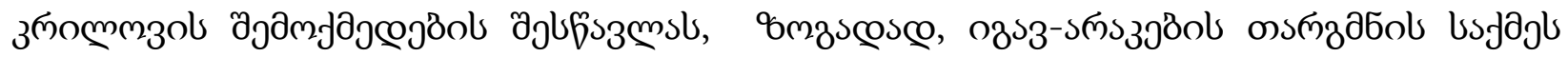
fsscosjos.

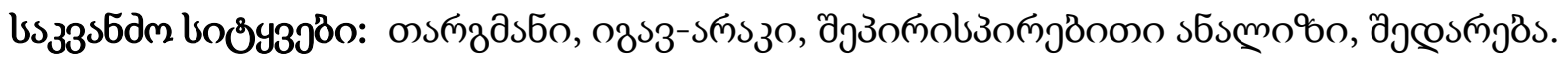

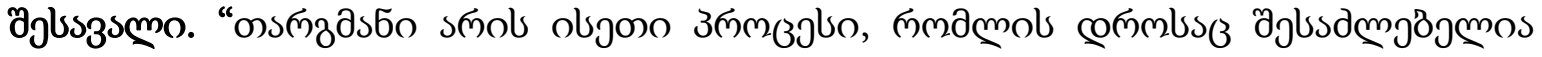

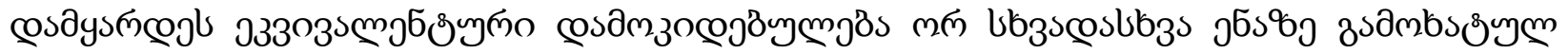

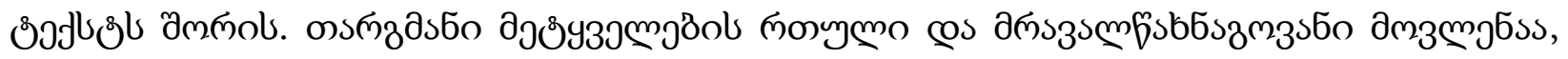

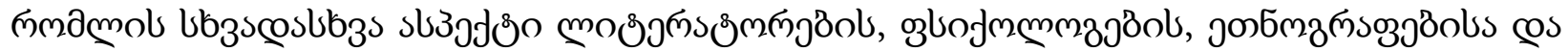

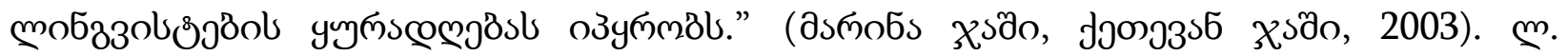

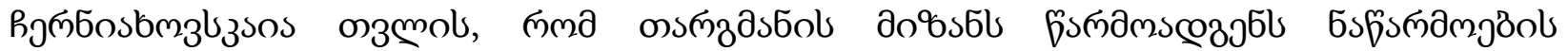

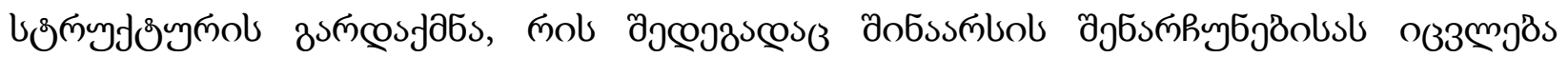

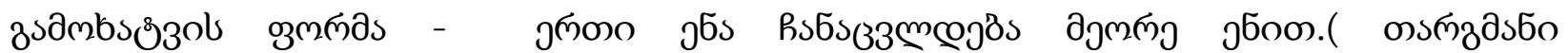
Язјбоз)(Черняховская Л., 1976).

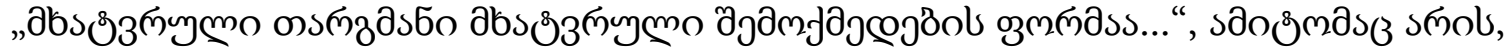

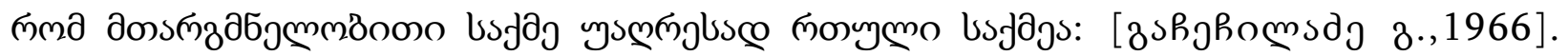

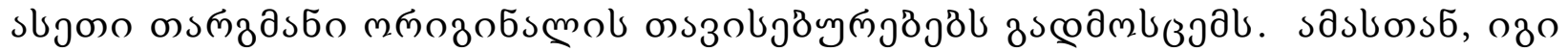

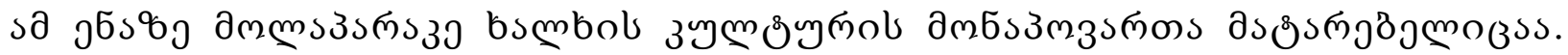

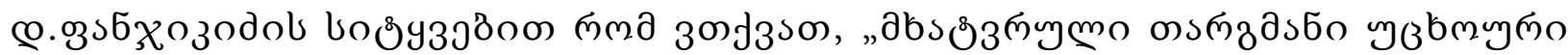

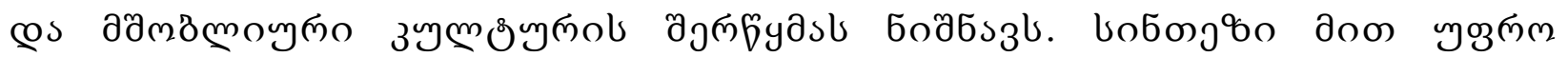

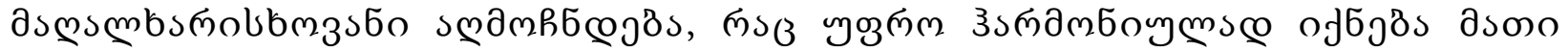

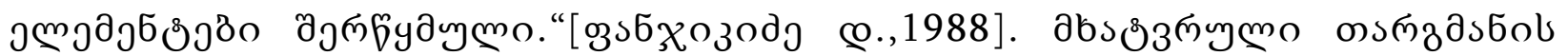

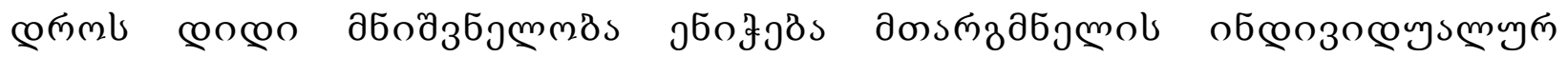

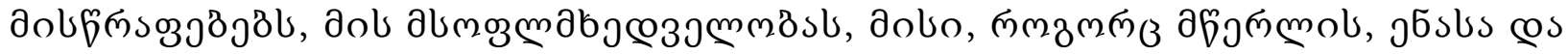
bo̊mb.

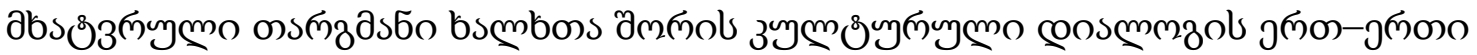

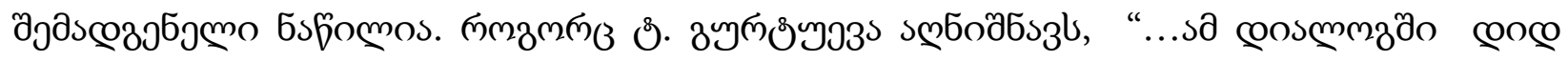

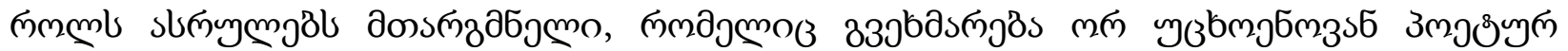

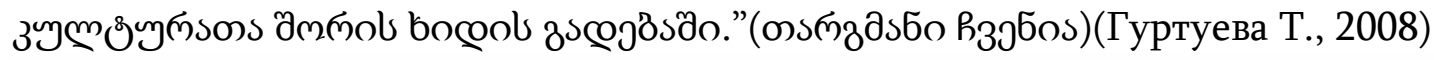

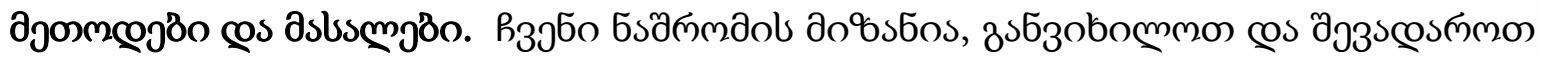

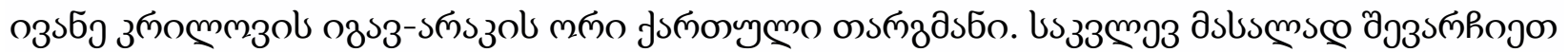

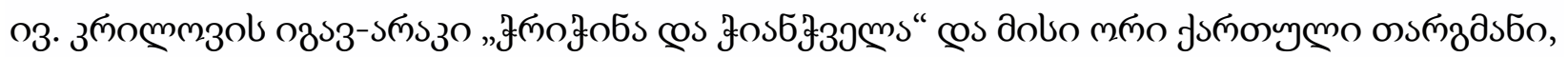

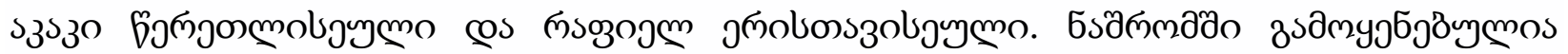

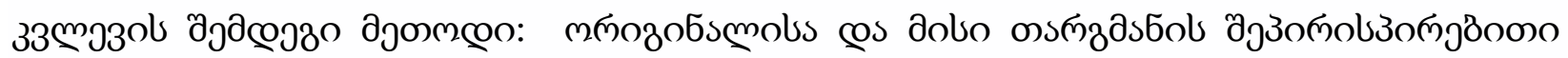
sбsmo\%o.

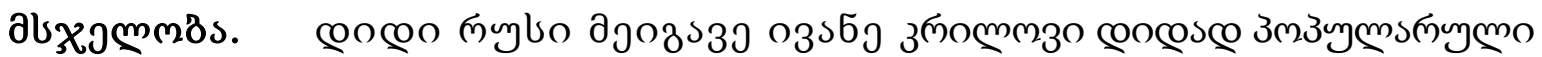

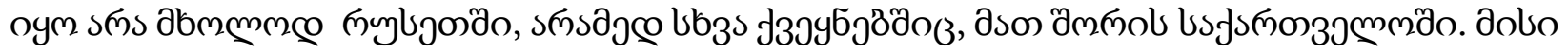

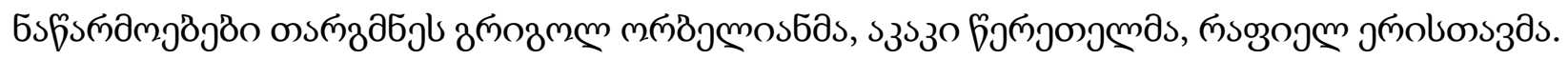

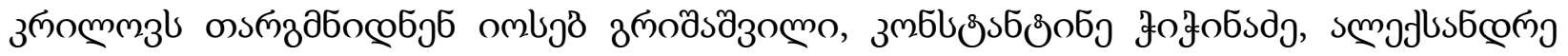




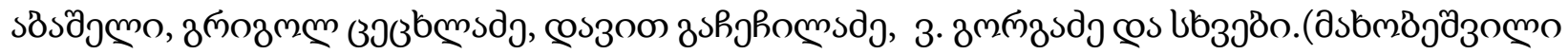
3., 2012).

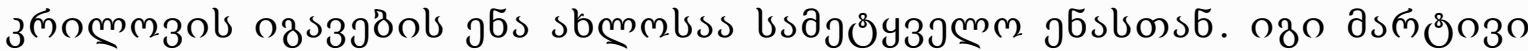

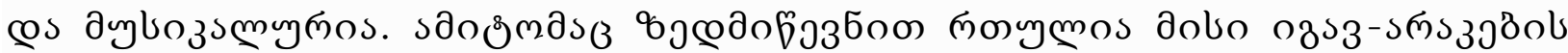

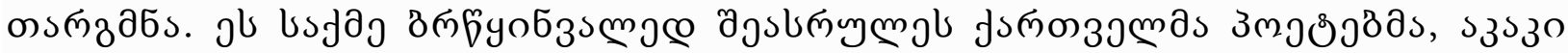

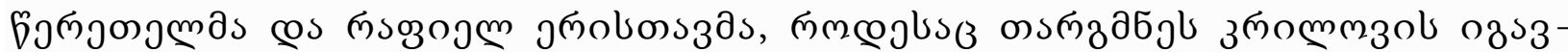

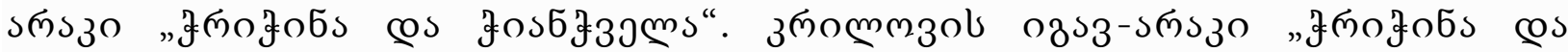

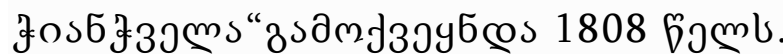
bachl.

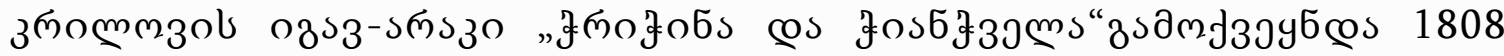

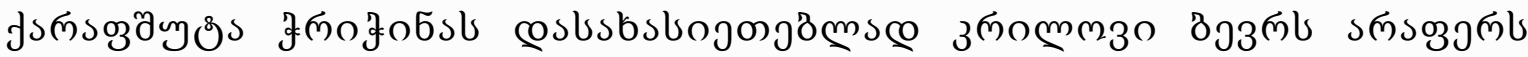

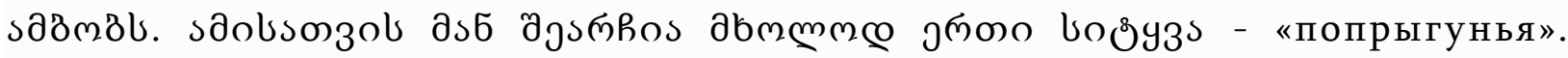

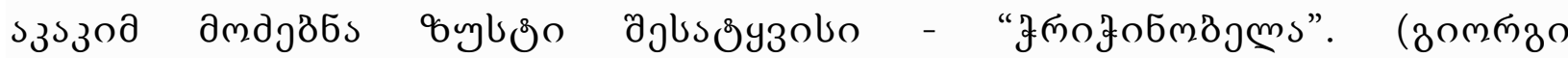
дsbmzృдзомо, 2012):

\section{Попрыгунья Стрекоза}

Лето красное пропела;

\section{Оглянуться не успела,-}

Как зима катит в глаза.

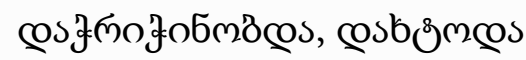

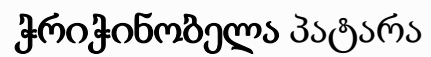

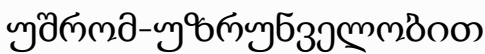

долgmo bsogbymo sôsms

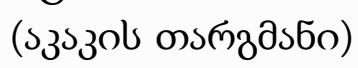

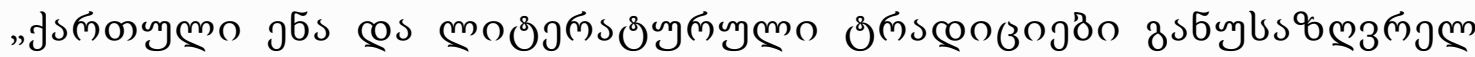

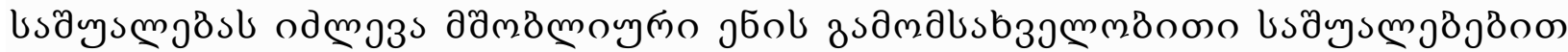

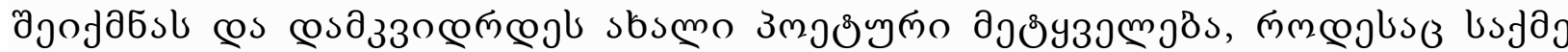

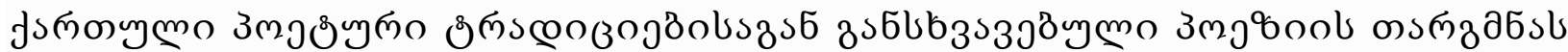

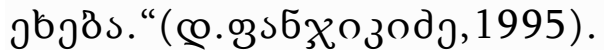

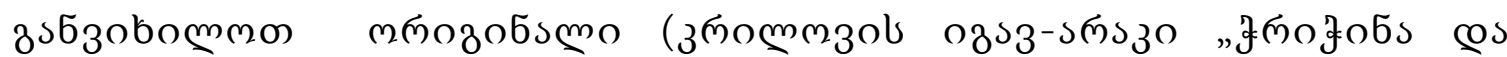

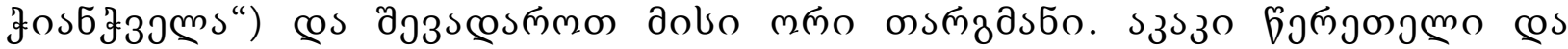

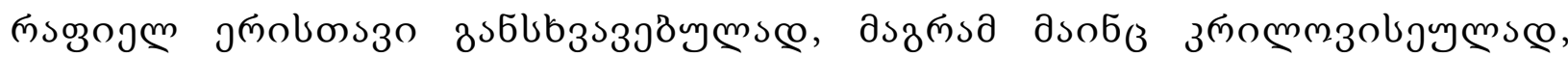

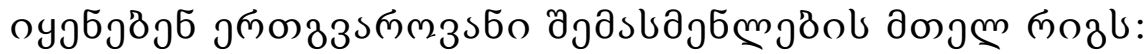

«Не оставь меня, кум милый!

Дай ты мне собраться с силой

И до вешних только дней

Прокорми и обогрей!»-

„คјдм Esonmos! 


\section{бч}

js

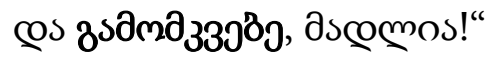

(oss

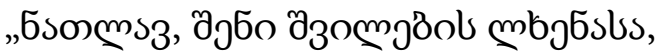

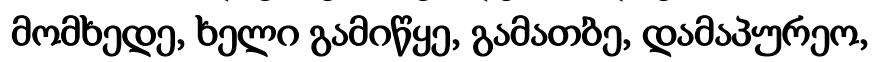

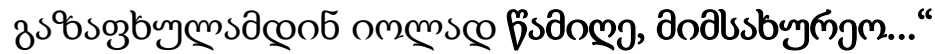

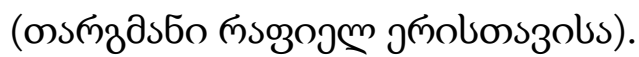

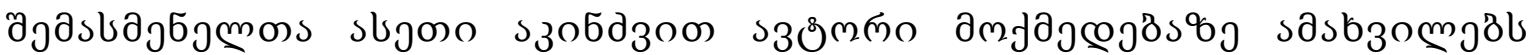

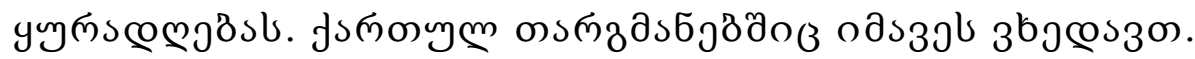

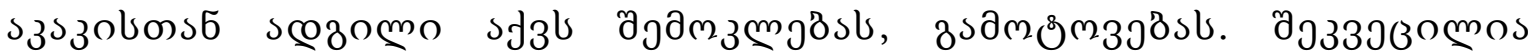

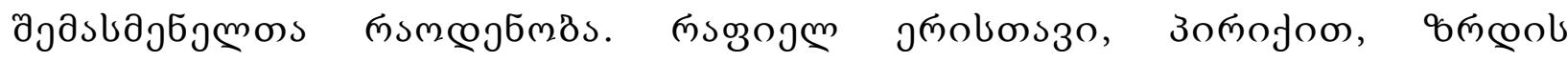

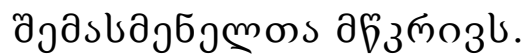

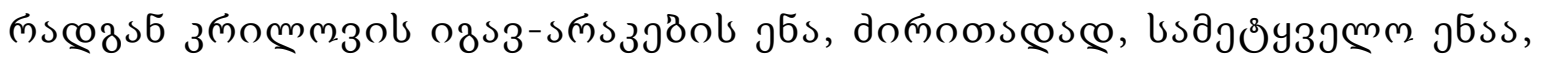

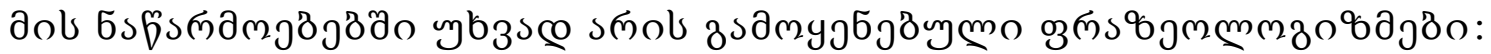

«До того ль, голубчик, было?

В мягких муравах у нас -

Песни, резвость всякий час,

Так что голову вскружило».-фразеологизм

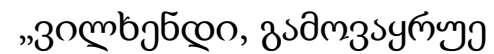

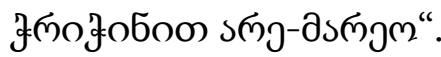

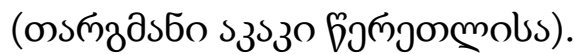

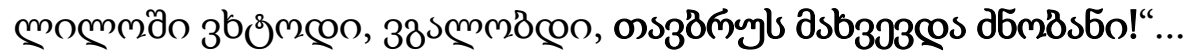

(onsmzas6o (nsogogm jnolonszols).

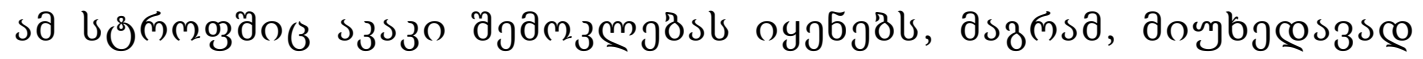

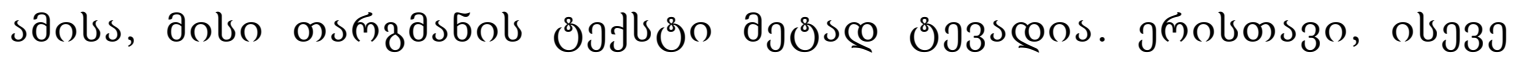

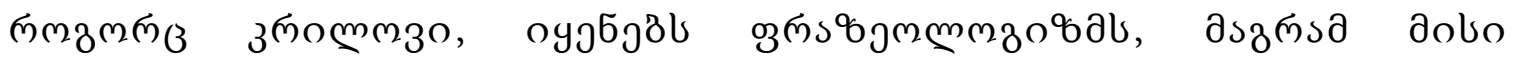

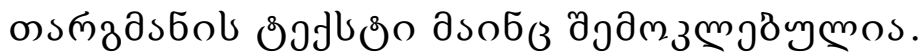

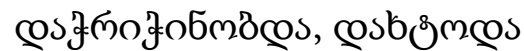

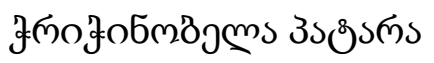

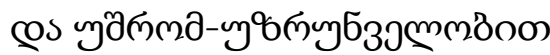

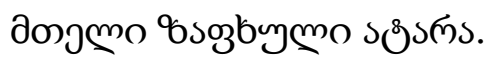

дзљґsа Попрыгунья Стрекоза

Лето красное пропела;

Оглянуться не успела,-фразеологизм

Как зима катит в глаза

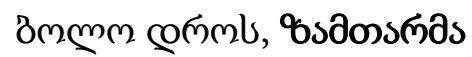

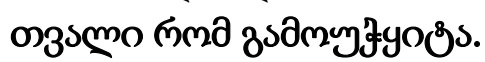

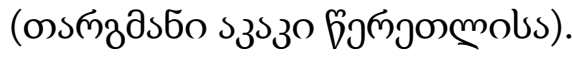




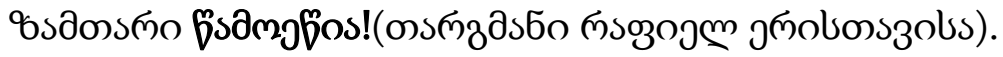

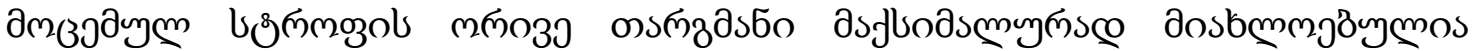
мங̆оzобsmoss.

\section{«Я без души -фразеологизм}

Лето целое всё пела».-

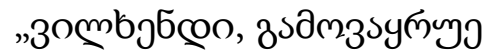

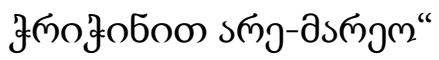

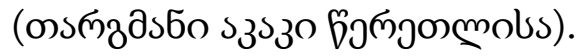

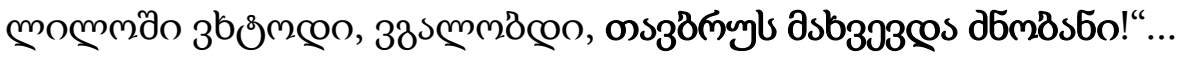

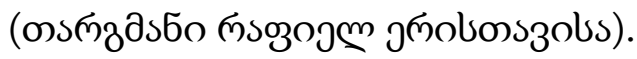

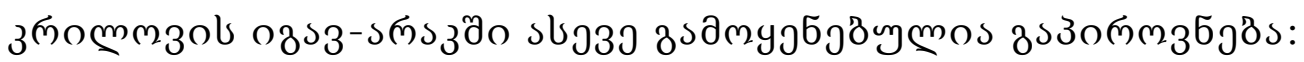

\section{Помертвело чисто поле;-олицетворение}

Нет уж дней тех светлых боле,

Как под каждым ей листком

Был готов и стол и дом.

Всё прошло: с зимой холодной

Нужда, голод настает;

Стрекоза уж не поет:

И кому же в ум пойдет

На желудок петь голодный -олицетворение

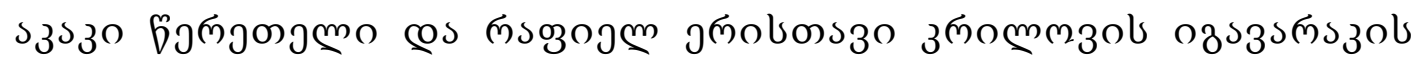

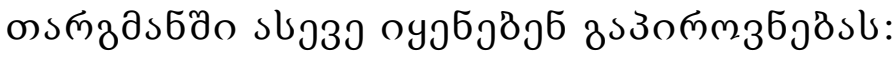

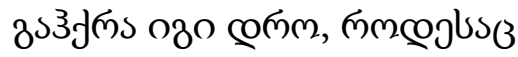

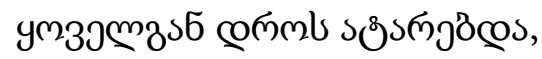

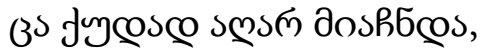

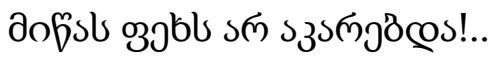

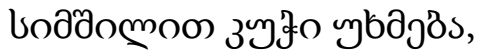

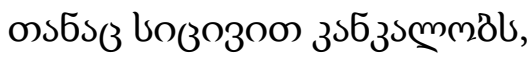

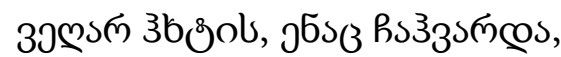

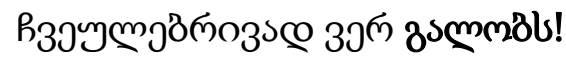

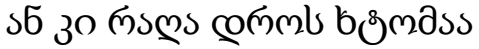

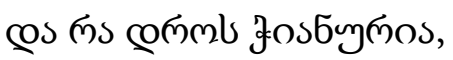

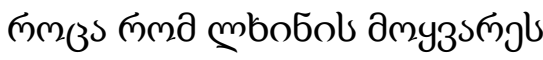

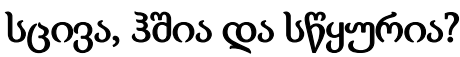

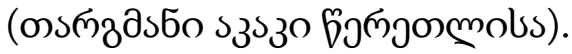

\begin{tabular}{|c|c|c|c|}
\hline 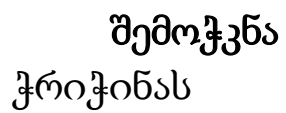 & $\begin{array}{l}\text { 39 mo, } \\
\text { zsabs }\end{array}$ & $\begin{array}{l}\text { аобеммпо, } \\
\text { јмбо, }\end{array}$ & 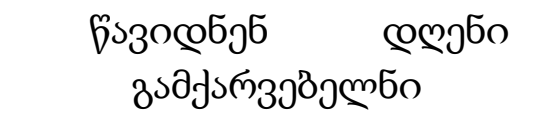 \\
\hline dst, & ymз30m & zusols & ylmy mejzిmess \\
\hline
\end{tabular}




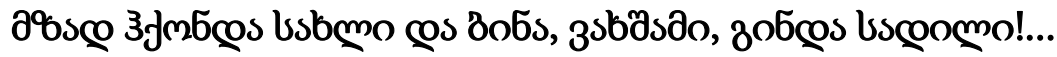

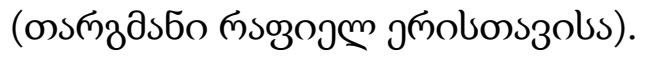

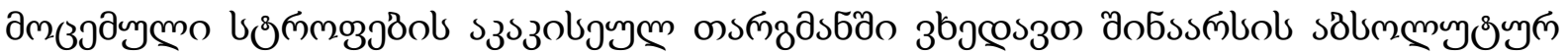

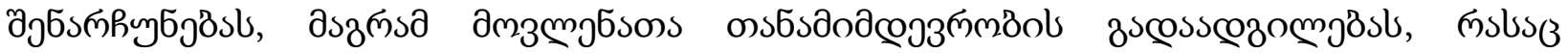

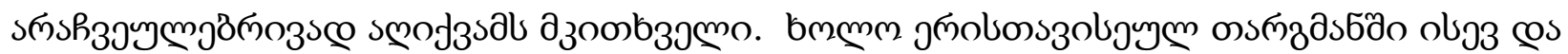
obj3 తి

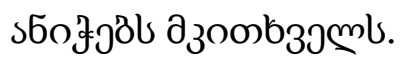

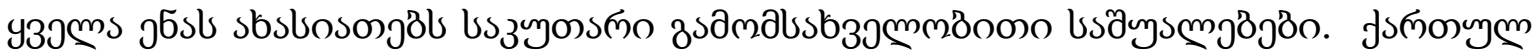

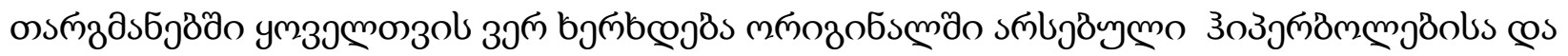
дэతిsоुм

Гипербола: -«лето целое все пела»

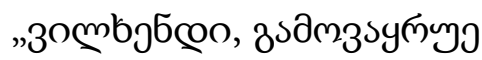

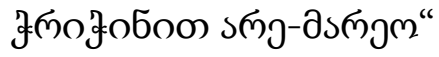

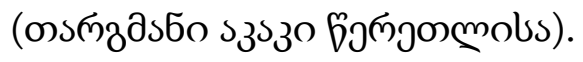

Метафоры: «лето красное пропела».

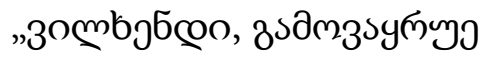

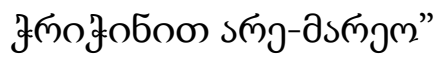

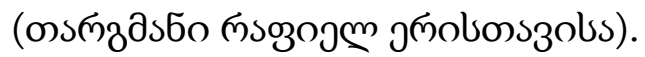

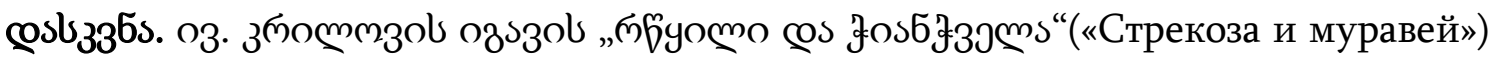

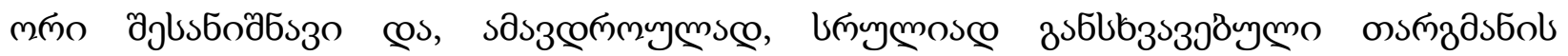

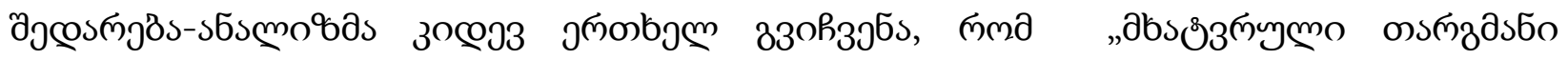

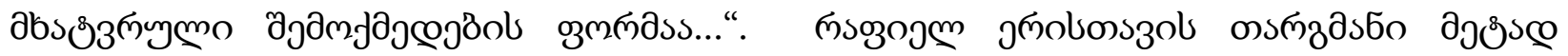

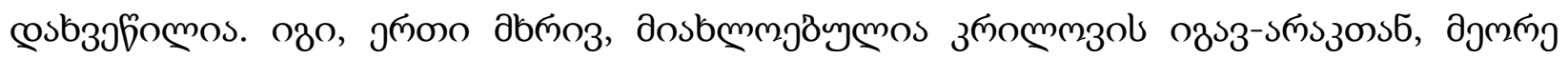

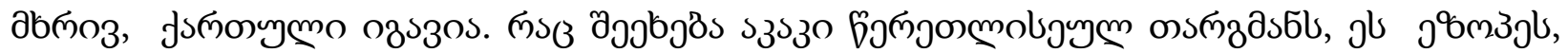

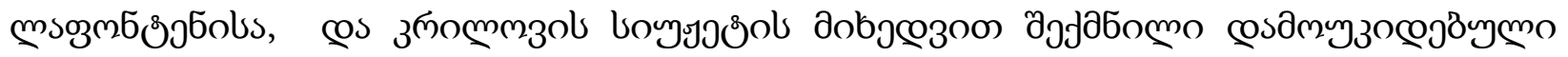
эвґб

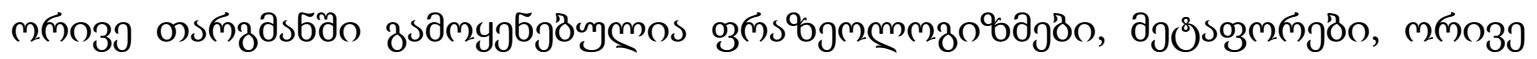

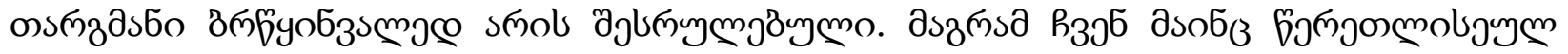

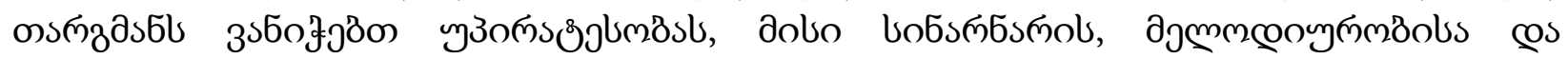

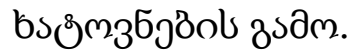

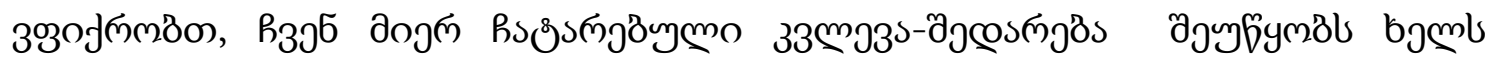

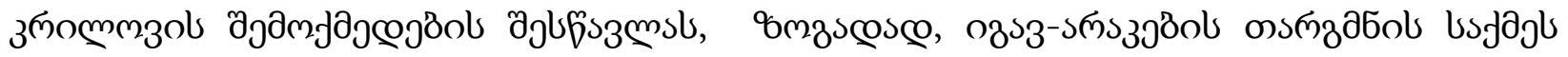
fuscojos.

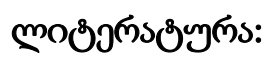




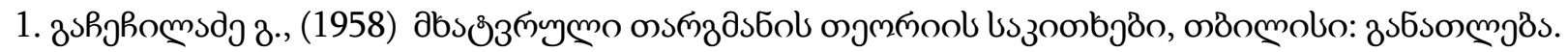

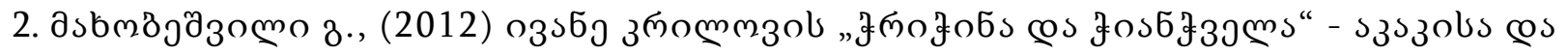

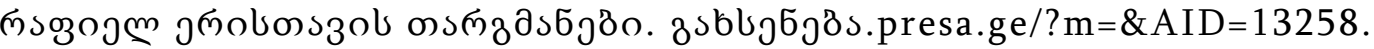

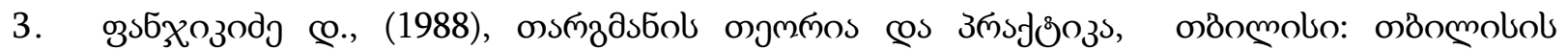

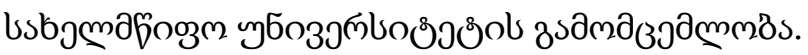

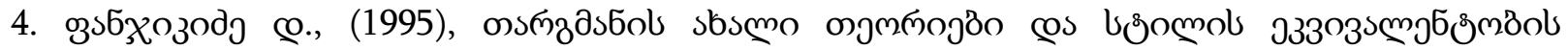

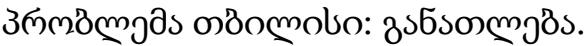

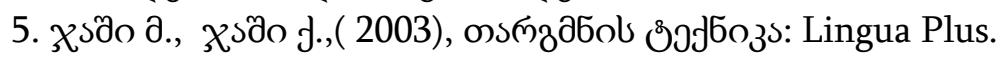

6.Гуртуева Т.(2008) Художественный перевод как составляющая культурного диалога. «Русский язык и культура в зеркале перевода. Материалы международной научно-практической конференции»:139

7.Черняховская Л. (1976) Перевод и смысловая структура. Москва: Международные отношения. 8.Герасимова Н.(2010) Курс лекций «Теория перевода».Ростов-на-Дону: РИНХ.

\title{
Two Georgian translations of Iv. Krylov's fable - "Dragonfly and Ant"
}

\author{
Seda Asaturova \\ Iakob Gogebashvili Telavi State University
}

\begin{abstract}
"Literary translation is a form of artistic creation ...", that is why translation is an extremely difficult task.

The aim of our paper is to consider the Georgian translations of Ivan Krylov's fables, to compare two different translations of the same fable.

We have selected Iv. Krylov's fable "Dragonfly and Ant" and his two Georgian translations, Akaki Tsereteli and Raphael Eristavi. The following research method is used in the paper: Contrastive - comparative analysis of the original text and its translation.

Akaki Tsereteli translated and rewrote Krylov 152 fables. Krylov was translated by Ioseb Grishashvili, Konstantine Chichinadze, Alexander Abasheli, Grigol Tsetskhladze, Davit Gachechiladze, V. Gorgadze and etc.

We have focused on two completely different translations of Krylov's fable ("The Dragonfly and the Ant"): Akaki Tsereteli and Raphael Eristavi.

Two Georgian writers translated this truly amazing work by Ivan Krylov. Akaki Tsereteli and Raphael Eristavi selected different ways of translation.

The translation of Raphael Eristavi is as close as possible to the original text: with word
\end{abstract}


order, with a carefully translated vocabulary, with an almost accurate translation of the phraseologies, with a sequence of the predicate.

Akaki Tsereteli has slightly adapted Krylov's fable, the writer presents an almost independent work and, at the same time, it is a brilliant translation.

Phraseologisms and metaphors are used in both translations, both translations are brilliantly executed. But we still prefer Tsereteli's translation because of its script, melody, and drawing.

We think that our research-comparison will contribute to the study of Krylov's work, in general, the translation of fables will be useful.

Key words: translation, fables, contrastive - comparative analyses, comparison 